\title{
Reclamações da comunidade à Seção de Controle de População Animal do Centro de Controle de Zoonoses de Niterói, Rj, Brasil, no período 2006-2010*
}

\section{Community complaints to the Animal Population Control Section of the Zoonosis Control Center of Niterói, RJ, Brazil, from 2006-2010}

\author{
Flavio Fernando Batista Moutinho, ${ }^{* *}$ Maurício Rafael Domingues Rocha, ${ }^{* * *}$ Fabio Villas Boas Borges, ${ }^{* * *}$ \\ Alessandra Gomes Pereira, ${ }^{* * *}$ Cathia Maria Barrientos Serra****
}

\begin{abstract}
Resumo
O presente estudo teve o objetivo de relatar as principais reclamações referentes a animais feitas pela comunidade à Seção de Controle de População Animal do Centro de Controle de Zoonoses de Niterói, RJ, no período de 2006 a 2010 , e assim avaliar possíveis fatores condicionantes e/ou determinantes e possíveis consequências. No período estudado foram registradas 1522 reclamações à Seção, com envolvimento de cães em 40,1\% ( $n=611)$, de pombos em 17,9\% ( $n=272)$, de suínos em 16\% ( $n=243)$, de morcegos em 10,7\% (n=164), de gatos em 7,6\% ( $n=116)$, de equinos em $4,7 \%(n=71)$, de aves $2 \%(n=30)$ e de outras espécies $1 \%(n=15)$. As principais causas de reclamações à Seção foram associadas à questão ambiental, ao crescimento desordenado da cidade e a hábitos inadequados da população, com prejuízos diversos, principalmente sanitários. Em face do exposto, pode se concluir que a mitigação da ocorrência desses problemas pode ser alcançada por intermédio de ações de educação em saúde, de ordenamento urbano e de fiscalização.
\end{abstract}

Palavras-chave: zoonoses, Niterói, população animal.

\begin{abstract}
The present study aimed to identify the main animals involved in complaints from population to the Animal Population Control Section of the Zoonosis Control Center Niterói, RJ, from 2006 to 2010 and to evaluate conditioning factors and/or determinants and possible consequences of these complaints. During the period studied the division received 1522 complaints, which $40.1 \%$ $(n=611)$ were about dogs, $17.9 \%(n=272)$ about pigeons, $16 \%(n=243)$ about pigs, $10.7 \%(n=164)$ about bats, $7.6 \%(n=116)$ about cats, $4.7 \%(n=71)$ about equine, $2 \%(n=30)$ about birds and $1 \%(n=15)$ about other animals. The main causes of the complaints were related to environmental issues, to the city growth and to poor hygienic habits of the population. It was concluded that mitigation of these problems can be achieved through actions of health education, urban planning, enforcement and using an health ecosystemic approach.
\end{abstract}

Keywords: zoonoses, Niterói, animal population.

\section{Introdução}

A história da convivência dos homens com os demais animais vem ocorrendo como uma aliança interespécies em que estes são considerados, muitas vezes, como membros da família. No entanto, em determinadas ocasiões, esta relação pode ser conflituosa (Faraco; Seminotti, 2004). Neste contexto, os animais vêm representando duas diferentes vertentes, ou seja, enquanto uma parte é objeto de desejo para preenchimento de lacunas emocionais ou pelo interesse econômico, a outra parte é abominada pela população, como no caso dos sinantrópicos, por exemplo (Silvano et al., 2010).

Apesar da maioria das enfermidades ser causada ou influenciada por fatores ambientais (Bonita et al., 2008), a domesticação dos animais também possibilita a criação de nichos artificiais que podem ser preenchidos por agentes etiológicos, funcionando como focos artificiais de enfermidades (Forattini, 2004).

Os Centros de Controle de Zoonoses (CCZ) são instituições públicas de saúde com competência e atribuição de atuar no controle de zoonoses, doenças transmitidas por vetores, agravos causados por animais peçonhentos e animais incômodos como moscas, simulídeos e baratas (Reichmann, 2000).

O município de Niterói, RJ, sempre teve destaque no cenário nacional brasileiro, tendo sido, inclusive, capital do Estado do Rio de Janeiro antes da fusão deste com o Estado da Guanabara (IBGE, 2012).

Segundo dados do Censo do IBGE de 2010, o Município conta com uma população de 487.327 habitantes em uma área de 129,3 km² (IBGE, 2012). É o município brasileiro com terceiro

\footnotetext{
* Recebido em 26 de outubro de 2012 e aceito em 4 de abril de 2013.

** Universidade Federal Fluminense, Faculdade de Veterinária, Departamento de Saúde Coletiva Veterinária e Saúde Pública e Prefeitura Municipal de

Niterói, Departamento de Vigilância Sanitária e Controle de Zoonoses. Niterói, RJ, Brasil. Autor para correspondência: flaviomoutinho@vm.uff.br.

*** Prefeitura Municipal de Niterói, Departamento de Vigilância Sanitária e Controle de Zoonoses. Niterói, RJ, Brasil.

**** Universidade Federal Fluminense, Faculdade de Veterinária, Departamento de Saúde Coletiva Veterinária e Saúde Pública. Niterói, RJ, Brasil.
} 
maior Índice de Desenvolvimento Humano, bem como o maior do Estado do Rio de Janeiro (PNUD, 2003) possuindo, ainda, a maior renda per capita domiciliar do País (IBGE, 2012).

O Centro de Controle de Zoonoses e Doenças de Transmissão Vetorial de Niterói (CCZ), RJ, é integrante da estrutura do Departamento de Vigilância Sanitária e Controle de Zoonoses (DEVIC), da Fundação Municipal de Saúde (FMS), e tem como funções a realização de ações de vigilância e controle de zoonoses. Na Seção de Controle de População Animal (SÇPOP) estão agrupadas as atividades que objetivam o controle de zoonoses associadas a animais domésticos, silvestres e sinantrópicos (Niterói, 1988a).

As zoonoses são «doenças e infecções que se transmitem naturalmente entre os animais vertebrados e o homem» (Corrêa, 1976). A raiva pode ser considerada a zoonose que serve de base à estruturação das ações zoossanitárias por parte dos CCZ (Domingos et al., 2007).

$O$ presente estudo teve o objetivo de relatar principais animais envolvidos nas reclamações da comunidade à SÇPOP no período de 2006 a 2010, avaliar possíveis fatores condicionantes e/ou determinantes e suas possíveis consequências.

\section{Material e métodos}

$\mathrm{Na}$ SÇPOP são registradas reclamações da comunidade por intermédio de dois fluxos de registro e tramitação: os processos abertos no Protocolo Geral do DEVIC e os Boletins de Pronto Atendimento (BPA), registrados na própria seção.

Foi efetuado um levantamento documental junto aos arquivos da Seção de Controle de População Animal do Centro de Controle de Zoonoses do município de Niterói, RJ, Brasil, em relação aos registros de reclamações da comunidade envolvendo animais, no período de 2006 a 2010.

Os dados foram tabulados e calculadas as frequências absoluta e relativa dos principais animais envolvidos nas reclamações.

Cabe aqui salientar que as reclamações referentes à proliferação de roedores e de invertebrados são direcionadas a outra seção do CCZ de Niterói, logo, não foi objeto de análise do presente estudo.

\section{Resultados e discussão}

No período de 2006 a 2010 foram efetuadas 1.522 reclamações à SÇPOP do $\mathrm{CCZ}$ de Niterói, conforme pode ser visualizado na Tabela 1, a seguir.

Ao se analisar os dados da Tabela 1, pode-se perceber que em todos os anos do período a preponderância das reclamações é daquelas relacionadas com cães, alcançando $40,1 \%$ das reclamações no somatório dos cinco anos analisados $(n=611)$. Se acrescentarmos às reclamações em relação a cães àquelas relacionadas com gatos, no total de 7,6\% $(n=116)$ no referido período, totaliza $47,7 \%$ das reclamações $(n=727)$ relacionadas com as duas principais espécies de animais de estimação criadas no Brasil. Tal situação era esperada, pelas transformações que a sociedade vem passando e que vêm ocasionando a redução do tamanho das famílias e o consequente aumento da busca afetiva nos cães e gatos de estimação (Silva et al., 2010).

A maioria dos municípios brasileiros enfrenta problemas com animais não domiciliados como crias indesejadas, superpopulação, abandono de animais, ausência de regras para criação e comercialização de animais, mordeduras, denúncias de maus-tratos e não observância às condições de bem-estar animal (Vieira et al., 2006), com predomínio em locais com baixos índices sociais (Shimozako et al., 2006). Em Niterói, este quadro se repetiu no período estudado, com relação a cães e gatos, sendo que as reclamações registradas estiveram relacionadas com maus-tratos, animais soltos nas ruas, excesso de animais nos domicílios, barulho, odor desagradável e más condições de higiene.

No que tange à ocorrência de zoonoses, deve-se ter atenção especial aos animais semidomiciliados ou parcialmente restritos, já que estes se relacionam diretamente tanto com os animais de rua quanto com seus proprietários ou cuidadores, no caso de animais comunitários, podendo ser o elo de uma fonte de infecção com um hospedeiro susceptível (Matos et al., 2002). É muito comum no Brasil os proprietários permitirem que seus cães tenham acesso sozinhos às ruas, aumentando o risco de transmissão de zoonoses (Nunes et al., 1997; Rigo et al., 2007; Silva et al., 2010; Silvano et al., 2010).

Nesse contexto, é de fundamental importância que os proprietários de animais adotem a posse responsável que, de acordo com Reichmann et al. (2000, p. 2), "pressupõe a manutenção constante de animais de estimação nos domicílios de seus proprietários, em boas condições de higiene e saúde e, quando a passeio, que sejam controlados através do uso de coleiras e de guias por pessoa com capacidade física para conduzi-los". Diversos estudos comprovam a carência da aplicação por parte dos proprietários de animais domésticos dessas práticas de guarda responsável (Limbert et al., 2009; Silva, 2009; Carvalho et al., 2011; Langoni et al., 2011; Netto et al., 2011) tornando-se extremamente importante o desenvolvimento de ações contínuas de sensibilização e educação sobre o assunto, como vem sendo feito em municípios como Palotina, PR (Guirro et al., 2008) e Ibiúna, SP (Soto; Bernardi, 2011). Os médicos-veterinários são atores sociais fundamentais nesse processo de sensibilização e conscientização da população envolvendo as necessidades dos animais domésticos e a relação destes com os humanos (Silvano et al., 2010). O CCZ de Niterói, por intermédio de seu setor de Informação, Educação e Comunicação em Saúde (IEC) desenvolve atividades educativas periódicas em relação à guarda responsável de animais de estimação, com a realização de palestras e oficinas, principalmente em unidades de ensino.

Em segundo lugar, quando considerado o somatório do período estudado, encontram-se as reclamações relativas à proliferação de pombos, representando $17,9 \%(n=272)$ do total. Outros órgãos de controle de zoonoses brasileiros também vêm registrando, com frequência, reclamações de cidadãos acerca da proliferação de pombos nas áreas urbanas (Schuller, 2005).

Os pombos são animais exóticos considerados sinantrópicos quando em vida livre e sua proliferação é um grave problema comum às cidades brasileiras, ocasionado pela disponibilidade de alimento e abrigo, principalmente em ambientes urbanizados, o que é agravado pela possibilidade de se reproduzirem durante a maior parte do ano (Nunes, 2003).

Apesar de no ambiente natural alimentarem-se de grãos e sementes (id., 2003), em ambientes antropizados têm ampliada a base alimentar, ingerindo diversos tipos de alimentos, como frutas, farelos de pão e biscoito e resíduos orgânicos em geral, sendo comuns em locais de grande afluxo de transeuntes 
Tabela 1: Frequência de reclamações da comunidade, por tipo de animal envolvido, à Seção de Controle de População Animal do CCZ de Niterói, RJ, Brasil, no período de 2006 a 2010

\begin{tabular}{l|ccccccc}
\hline \multicolumn{1}{c|}{ Animal } & $\mathbf{2 0 0 6}$ & $\mathbf{2 0 0 7}$ & $\mathbf{2 0 0 8}$ & $\mathbf{2 0 0 9}$ & $\mathbf{2 0 1 0}$ & $\begin{array}{c}\text { Total } \\
\text { (n) }\end{array}$ & $\begin{array}{c}\text { Frequência } \\
\text { relativa (\%) }\end{array}$ \\
\hline Cão & 55 & 136 & 119 & 163 & 138 & 611 & 40,1 \\
Pombo & 51 & 67 & 48 & 56 & 50 & 272 & 17,9 \\
Suíno & 10 & 36 & 41 & 67 & 89 & 243 & 16 \\
Morcego & 35 & 37 & 27 & 39 & 26 & 164 & 10,7 \\
Gato & 17 & 24 & 15 & 35 & 25 & 116 & 7,6 \\
Equino & 9 & 10 & 6 & 24 & 22 & 71 & 4,7 \\
Ave doméstica & 5 & 8 & 1 & 6 & 10 & 30 & 2 \\
Outro & 1 & 4 & 1 & 5 & 4 & 15 & 1 \\
\hline Total & $\mathbf{1 8 3}$ & $\mathbf{3 2 2}$ & $\mathbf{2 5 8}$ & $\mathbf{3 9 5}$ & $\mathbf{3 6 4}$ & $\mathbf{1 5 2 2}$ & $\mathbf{1 0 0}$ \\
\hline
\end{tabular}

Ambiente e Recursos Naturais Renováveis) como aves domésticas e, também, como sinantrópicas nocivas, sendo o seu controle regido pela Instrução Normativa Ibama ${ }^{\circ}$ 141, de 03/08/2006. Seu controle direto é permitido para órgãos estatais de Saúde, Agricultura e Meio Ambiente, sem que haja necessidade de autorização do Ibama, ou, ainda, por pessoas físicas ou jurídicas para tal habilitadas, desde que as ações sejam precedidas de uma declaração de nocividade a ser emitida por órgão estatal de uma das áreas supramencionadas. Dentre as ações de controle de fauna previstas encontram-se a captura seguida de soltura, com marcação, esterilização ou administração de fármacos; captura seguida de remoção; captura seguida de eliminação e eliminação direta de animais,

como praias e praças (Schuller, 2005). Em Niterói é frequente a presença de pombos em praias, praças e demais logradouros públicos, bem como nas edificações, o que gera uma série de conflitos entre a população.

A disponibilidade de alimentos e de locais propícios para a nidificação em vãos e frestas protegidos de intempéries existentes em imóveis e construções e a ausência de predadores naturais possibilitam o crescimento da quantidade dessa espécie nas cidades (Nunes, 2003). O deslocamento para outras áreas pode ocorrer relacionado à dificuldade em se conseguir alimentos, ocasião em que estas aves podem se deslocar centenas de metros em busca de alimento (Schuller, 2005).

Essa proliferação de pombos traz prejuízos de ordem econômica como o entupimento de calhas pelas penas e restos de ninhos (id., 2003) e o acúmulo de excretas em imóveis e logradouros públicos, que intensificam o apodrecimento de forros de madeira e danificam pinturas (Bencke, 2007). Porém, a referida proliferação representa, com maior gravidade, risco sanitário à população pois, além de atrair roedores e insetos sinantrópicos (id., 2007), os pombos podem agir como fonte de infecção para os agentes de doenças como histoplasmose, clamidiose, aspergilose, salmonelose, dermatites, alergias respiratórias e criptococose (Acha; Szyfres, 2003; Nunes, 2003; Bencke, 2007). esta somente se esgotadas todas as outras medidas de manejo. A infração à referida Instrução Normativa sujeita os infratores às penalidades previstas na Lei $n^{\circ}$ 9605/1998, de 12 de fevereiro de 1998, conhecida como Lei de Crimes Ambientais (Brasil, 2006).

As reclamações relativas a suínos aparecem em terceiro lugar, com 16\% $(n=243)$ dos registros. Cabe destacar o crescimento consistente desse tipo de reclamação, passando de dez, em 2006, para $89 \mathrm{em} \mathrm{2010,} \mathrm{o} \mathrm{que} \mathrm{equivale} \mathrm{a} \mathrm{um} \mathrm{incremento} \mathrm{de}$ $890 \%$, conforme pode ser visualizado na Figura 1.

As reclamações acerca de porcos envolvem os animais soltos nas ruas e as criações domiciliares. Além dessas criações serem irregulares de acordo com a legislação municipal (Niterói, 1988b), deve-se destacar o risco sanitário a que fica exposta a população, seja pelo contato direto com esses animais ou seus excrementos, seja pelo possível consumo de sua carne, situações em que a possibilidade de ocorrência de enfermidades zoonóticas graves é uma realidade. Os porcos podem funcionar como fonte de infecção e de parasitas de caráter zoonótico como os responsáveis pelo complexo teníase-cisticercose, a ascaridiose, o bicho-de-pé, a sarna, a salmonelose e a brucelose, dentre outras (Corrêa, 1976; Vianna, 1988; Acha; Szyfres, 2003). Destaca-se, ainda, o risco de acidentes de trânsito, já que um porco pode pesar mais de $250 \mathrm{~kg}$ (id.,
A prevenção e o controle da proliferação de pombos devem ser feitos com a integração de diversas medidas, principalmente de manejo ambiental (Bencke, 2007) que passam pela supressão das fontes de alimentação (Nunes, 2003; Bencke, 2007) e o impedimento de acesso aos abrigos e locais de reprodução (id., 2007), sendo complementadas pela limpeza e destinação adequada de resíduos em geral e ações de educação em saúde e mobilização social (Nunes, 2003). Importante salientar a ineficácia a longo e médio prazo dos métodos de controle letais pela possibilidade de crescimento do número de animais mais jovens e prolíficos, intensificando o processo reprodutivo (Bencke, 2007).

Ainda no que diz respeito ao controle e prevenção de pombos, cabe destacar que estas aves são classificadas pelo Ibama (Instituto Brasileiro do Meio

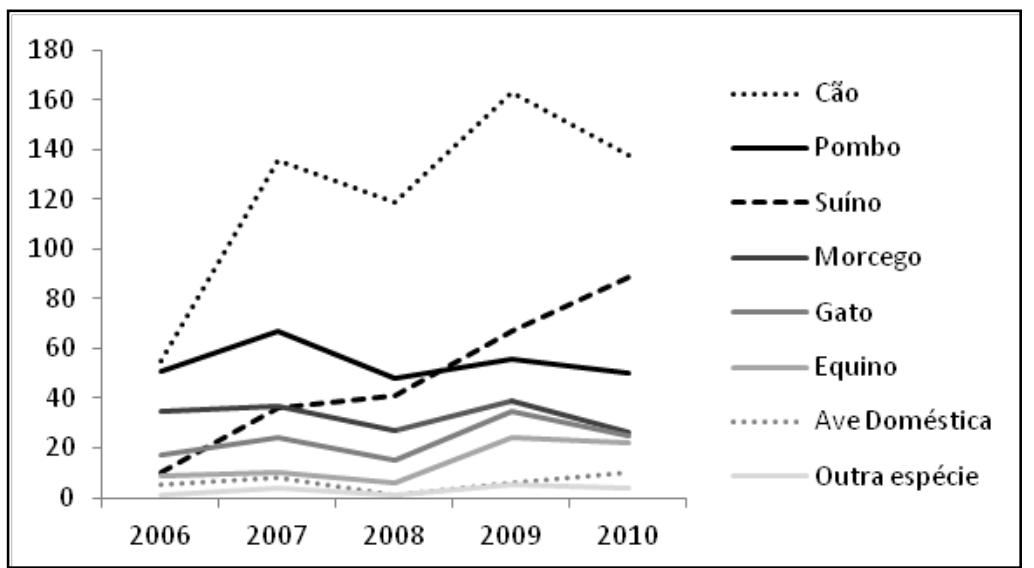

Figura 1: Variação, por animal, da frequência de reclamações da comunidade à Seção de Controle de População Animal do CCZ de Niterói, RJ, Brasil, no período de 2006 a 2010 
1988) e a questão da poluição ambiental pelos excrementos desses animais, pois um suíno adulto produz em torno de 0,27 $\mathrm{m}^{3}$ de dejetos/mês e, comparativamente ao esgoto doméstico produzido por humanos, os dejetos dos suínos são 260 vezes mais poluentes (Lovatto, 2002).

As reclamações referentes a morcegos representaram 10,8\% $(n=164)$ dos registros. As alterações ambientais vêm muitas vezes expulsando os morcegos de seu ambiente natural, o que os leva a procurar abrigo e alimento em áreas urbanizadas (Brasil, 2009a). A ampliação do processo de urbanização, que faz com que as áreas urbanas se aproximem ou mesmo invadam as áreas florestadas reduzem a capacidade de provisão dos ecossistemas, bem como a capacidade de regulação da ocorrência de doenças a eles inerente (Freitas; Porto, 2006). Tanto no caso dos pombos como no caso dos morcegos, que estão relacionados com problemas ambientais e não necessariamente da domiciliação voluntária de animais, fica claro que "nas vigilâncias em saúde, especialmente nas vigilâncias sanitária e ambiental, o enfoque de risco apresenta uma característica bem marcante: o risco à saúde não "respeita" território geográfico, divisas ou fronteiras" (De Seta; Pepe, 2008, p. 24).

Os morcegos não hematófagos vêm encontrando nos ambientes antropizados condições adequadas à convivência interespécies. As construções urbanas muitas vezes lhes fornecem abrigo, a arborização urbana com frutíferas fornece alimentos para os morcegos frugívoros e a iluminação de imóveis e logradouros públicos atraem insetos que servem de alimento para morcegos insetívoros (Brasil, 1988).

Apesar de poderem servir de fonte de infecção para agentes de diversas enfermidades, como a histoplasmose, por exemplo (Acha; Szyfres, 2003), atenção principal deve ser dada à raiva, pois, além do ciclo urbano, onde os principais envolvidos são o cão e o gato, a raiva silvestre envolvendo principalmente primatas e morcegos também é considerada um problema de saúde pública, em vista do crescimento desse tipo de transmissão no Brasil (OPAS; Brasil, 2002), inclusive no Estado do Rio de Janeiro (Oliveira et al, 2010). Além disso, deve-se considerar que o risco de transmissão do vírus pelo morcego é sempre elevado, independentemente da espécie e gravidade do ferimento. Logo, toda agressão por morcego deve ser classificada como grave (Brasil, 2009b).

Considerando a constante destruição do ambiente natural para a expansão urbana e a construção de moradias e levando-se em conta que o município de Niterói ficou dois anos seguidos sem realizar a Campanha de Vacinação Antirrábica de cães e gatos, tendo em vista a suspensão da mesma pelo Ministério da Saúde em função de eventos adversos ocasionados pela vacina em 2010 (Brasil, 2010), o risco de ocorrência de um caso de

\section{Conclusões}

Em face do exposto, pode-se concluir que as principais causas de reclamações da população à SÇPOP do CCZ de Niterói estão associadas à questão ambiental, ao crescimento desordenado da cidade e aos hábitos inadequados da população.

Nesse contexto, o desenvolvimento de ações de educação em saúde pode ser considerado extremamente importante para sensibilizar os munícipes e mitigar os impactos oriundos de maus hábitos como criações irregulares e em condições higiênicosanitárias insatisfatórias, bem como da disponibilização voluntária ou involuntária de alimentos para pombos. raiva no município tende a aumentar, já que a baixa cobertura vacinal canina (Brasil, 2009b) e as alterações ambientais (Brasil, 2009a) são considerados fatores de risco para a ocorrência da doença. Apesar da baixa ocorrência da raiva urbana no Brasil atualmente, a mesma ainda acontece de maneira esporádica, como o recente caso de raiva felina causada por variante viral relacionada com morcego hematófago (variante 3) que ocorreu em Jaguariúna, São Paulo (Moraes et al., 2011).

As reclamações referentes a equinos alcançaram 4,7\% $(n=71)$ das registradas no período estudado. Da mesma maneira que os suínos, os equinos encontram restrição legal à sua criação no Município (Niterói, 1988b). As referidas reclamações são ocasionadas pelos animais criados com objetivo de lazer, esporte ou transporte de cargas. Nessa questão considerase que, além da possibilidade de acidentes de trânsito com equinos porventura soltos nas ruas, não deve ser negligenciada a possibilidade de ocorrência da Febre Maculosa, que é uma enfermidade zoonótica grave cujos cavalos funcionam como fonte de infecção e seus carrapatos, da espécie Amblyomma cajennense, funcionam como vetores (Acha; Szyfres, 2003). Em 2009 houve um caso notificado e que resultou em óbito por Febre Maculosa humana no Município (Brasil, 2012).

As aves de produção, principalmente frangos, perus e patos participaram com $2 \%(n=30)$ dos registros no período. Estas, que são criadas como animais ornamentais, ou, ainda, como fonte de proteína, não encontram na legislação municipal nenhuma restrição direta à sua criação, como no caso de suínos e equinos. Por fim, outras espécies como ovelhas, coelhos e cabras também foram, com $1 \%(n=15)$ dos casos, objeto de reclamações da comunidade, geralmente em função das condições sanitárias e odor desagradável.

Baseado no exposto, fica visível que os principais problemas que são objetos de reclamação da população junto ao CCZ estão relacionados com problemas ambientais - como a destruição de habitats no caso dos morcegos e a introdução de espécies exóticas como os pombos - e de urbanização e hábitos culturais da população, como no caso dos cães e gatos, dos suínos e dos equinos, dentre outros. Nesse contexto é importante destacar as condições dos domicílios, do saneamento ambiental, climáticas e socioeconômicas influenciam diretamente na ocorrência de doenças transmissíveis, que também são condicionadas por fatores como hábitos e comportamentos individuais (Barcellos, 2008).

O desenvolvimento de um (ambiente saudávelı, que exige ações intersetoriais e políticas públicas integradas entre os entes governamentais e a sociedade civil, deve levar em conta esses problemas, que vêm gerando reclamações ao CCZ (Brasil, 2007).

Romper com o modelo atual de atuação e com o paradigma cartesiano unicausal das enfermidades e buscar uma abordagem ecossistêmica pode ser a melhor opção para a mitigação e resolução dos problemas encontrados.

Por fim, pode-se concluir que o formato de registro de reclamações na SÇPOP vigente é um óbice à elaboração de estudos que possibilitem uma análise crítica da frequência das mesmas. Sugere-se o aperfeiçoamento dos mecanismos de registros de dados de forma a permitir o devido esclarecimento sobre a causalidade das mesmas, não ficando restrita à identificação da espécie envolvida. 


\section{Referências}

ACHA, P. N; SZYFRES, B. Zoonosis y enfermedades transmisibles comunes al hombre y a los animales. 3. ed. Washington, D. C.: Organización Panamericana de la Salud, 2003. 3 vol.

BARCELLOS, C. Problemas emergentes da saúde coletiva e a revalorização do espaço geográfico. In: MIRANDA, A. C. et al. Território, ambiente e saúde. Rio de Janeiro: Fiocruz, 2008, p. 4356.

BENCKE, G. A. Pombos-domésticos: sugestões para o controle em Escolas Públicas Estaduais de Porto Alegre. Porto Alegre: Museu de Ciências Naturais / FZB-RS / 1 a CRE/SE, 2007. 22 p.

BONITA, R.; BEAGLEHOLE, R.; KJELLSTROM, T. Epidemiología básica. Washington D. C.: Organização Panamericana de Saúde, 2008, 269 p.

BRASIL. Ministério da Saúde. Morcegos em áreas urbanas e rurais: manual de manejo e controle. Brasília, DF: Fundação Nacional de Saúde, 1988. 117 p.

BRASIL. Ministério do Meio Ambiente. IBAMA. Instrução Normativa $\mathrm{n}^{\circ} 141$, de 19 de dezembro de 2006. Regulamenta o manejo e controle ambiental da fauna sinantrópica nociva. Disponível em: www.ibama.gov.br. Acessado em 25 de junho de 2011.

BRASIL. Ministério da Saúde. Conselho Nacional de Saúde. Subsídios para construção da Política Nacional de Saúde Ambiental. Brasília, DF: Ministério da Saúde, 2007. 56 p.

BRASIL. Ministério da Agricultura, Pecuária e Abastecimento. Controle da raiva dos herbívoros: manual técnico. Brasília, DF: MAPA, 2009a. 124 p.

BRASIL. Ministério da Saúde. Secretaria de Vigilância em Saúde. Guia de Vigilância Epidemiológica. 7. ed. Brasília, DF: Ministério da Saúde, 2009b. 816 p.

BRASIL. Ministério da Saúde. Secretaria de Vigilância em Saúde. Nota Técnica n 161/2010 DEVEP/SVS/MS. Disponível em: http:// portal.saude.gov.br/portal/arquivos/pdf/nt_161_vacina_contra_ raiva_animal_2.pdf. Acessado em 29 de setembro de 2012.

BRASIL. Ministério da Saúde. DATASUS. Disponível em: http://dtr2004.saude.gov.br/sinanweb/tabnet/tabnet?sinannet/ fmaculosa/bases/febremaculosabrnet.def. Acessado em 25 de setembro de 2012.

CARVALHO, A., GRISÓLIO, A., BUENO, G., TESTI, A., MARTINS, M., PORTELA, L., SERVIDONE, J., NUNES, J. Caracterização da população de cães e gatos e avaliação do nível de conhecimento dos moradores sobre zoonoses e posse responsável de animais de estimação em bairros do município de Jaboticabal / SP. Rev. Ciênc. Ext., v. 7, n. 2, p.158-159, 2011.

CORREAA, O. Doenças parasitárias dos animais domésticos. Porto Alegre: Sulina, 1976. 374 p.

De SETA, M. H.; PEPE, V. L. E. Vigilâncias em Saúde. Rio de Janeiro: EAD/ENSP, 2008. 90 p.

DOMINGOS, I. H.; RIGO, L.; HONER, M. R. Perfil da populações canina e felina no município de Campo Grande, MS. Ensaios e cien..., v. 11, n. 1, p. 97-103, 2007.

FARACO, C. B.; SEMINOTTI, N. A relação homem/animal e a prática veterinária. Revista CFMV. v. 10, n. 32, p. 57-62, 2004.

FORATTINI, O. P. Ecologia, epidemiologia e sociedade. 2. ed. São Paulo: Artes Médicas, 2004. 710 p.

FREITAS, C. M.; Porto, M. F. Saúde, meio ambiente e sustentabilidade. Rio de Janeiro: Fiocruz, 2006. 124 p.

GUIRRO, E. C. P. B.; LEMES, K. M.; RIBEIRO, S. L., BINI, SILVA, M. M.; BINI, T. L.; CUNHA, O. Implantação do conceito de "Posse Responsável" no município de Palotina / PR - Brasil. Extensão em foco, v. 2, p.155 -159, 2008.
IBGE. Cidades. Niterói. Disponível em: www.ibge.gov.br. Acesso em 26 de outubro de 2012.

LANGONI, H; TRONCARELLI, M. Z.; RODRIGUES, E. C.; NUNES, H. R. C.; HARUMI, V.; HENRIQUES, M. V.; SILVA, K. M.; SHIMONO, J. Y. Conhecimento da população de Botucatu - SP sobre Guarda Responsável de cães e gatos. Vet. e Zootec., v. 18, n. 2, p. 297-305, 2011.

LIBERTI, B. N. P.; MENEZES, J. S.; FERNANDES, S. S. P. Estudo da tríade: educação sanitária, posse responsável e bem-estar animal em animais de companhia em comunidades de baixa renda. Anuário de produção de iniciação científica discente, v. 12, n. 13, p. 99-108, 2009.

LOVATTO, P. A. Manejo de dejetos. In: Suinocultura geral. p.6383, Santa Maria: UFSM, 2002. Disponível em: http://w3.ufsm.br/ suinos/CAP9_dej.pdf. Acesso em 29 de março de 2013.

MATOS, M. R.; ALVES, M. C. G. P.; REICHMANN, M. L. A. B.; DOMINGUEZ, M. H. S. Técnica Pasteur São Paulo para dimensionamento de população canina. Cad. Saúde Pública, v. 18, n. 5, p.1423-1428, 2002.

MORAES, J. E. C.; ZANATA, A. F.; THOMÉ, C. M.; MOREIRA, D. C. B.; PRESSOTO, D.; COSTA, I. C.; BORGES, M. S.; RODRIGUES, R. C. A.; MARTINS, R. S. Raiva felina no município de Jaguariúna, Estado de São Paulo, em 2010. BEPA, v. 8, n. 96, p. 4-10, 2011.

NETTO, L. C.; LIMA, F. F.; PERRI, S. H. V.; KOIVISTO, M. B.; BRESCIANI, K. D. S. Programa de conscientização de idosos sobre posse responsável de animais de estimação em bairro periférico do município de Araçatuba, SP. Rev. Ciênc. Ext., v. 7, n. 2, p. 102-109, 2010.

Niterói. Decreto $n^{\circ} 5495$ de 01 de novembro de 1988. Fica aprovado o Regimento nterno do Centro de Controle de Zoonoses Prof. Américo Braga, criado pelo Decreto $n^{\circ} 4962 / 1987$. Diário Oficial da municipalidade, Niterói, RJ, p.1, 3 nov 1988a.

Niterói. Lei $n^{\circ} 726$ de 28 de dezembro de 1988. Dispõe sobre o controle de populações animais e sobre a prevenção e o controle de zoonoses no Município de Niterói. Diário oficial da municipalidade, Niterói, RJ, p. 7, 29 dez 1988b.

NUNES, V. F. P. Pombos urbanos: o desafio de controle. Biológico, São Paulo, v. 65, n. 12, p. 9-92, 2003.

NUNES, C. M.; MARTINES, D. A.; FIKARIS, S.; QUEIRÓZ, L. H. Avaliação da população canina da zona urbana do município de Araçatuba, São Paulo, SP, Brasil. Revista de Saúde Pública, v. 31, n. 3, p.308-309, 1997.

OLIVEIRA, A. S. S.; BEZERRA, F. F. M.; AZEVEDO, F. R. M.; CARVALHO, S. C. Descrição do perfil epidemiológico da raiva no Estado do Rio de Janeiro no período de 1981 a 2007. Revista Rede de Cuidados em Saúde, v. 4, n.2, p.1-12, 2010.

OPAS; Brasil. Ministério da Saúde. Avaliação do Programa Nacional de Controle da Raiva no Brasil. Disponível em http:// www.paho.org/cdmedia/hdmvp01/docs.rabia/paises/EVAL.RABIA. BRASIL.pdf. Acesso em 04 de agosto de 2011.

PNUD. Ranking do IDH dos Municípios do Brasil 2003. Disponível em: http://www.pnud.org.br/atlas/ranking/IDH_Municipios_Brasil_ 2000.aspx? indiceAccordion $=1 \&$ li $=$ li_Ranking2003. Acesso em $2 \overline{6}$ de outubro de 2012.

REICHMANN, M. L. A. B. Orientação para projetos de Centros de Controle de Zoonoses. 2. ed. São Paulo: Instituto Pasteur, 2000 (Manuais, 2) $45 \mathrm{p}$.

SCHULLER, M. Pombos urbanos: em caso de saúde pública. Revista da SBCC, v. 29, p. 32-37, 2005.

SHIOZAKO, H. J. et al. Uso de sistemas de informação geográfica como ferramentas de auxílio na análise de casos de apreensão de animais no município de São Paulo. Rev. Ciênc. Ext., v. 2, n. 2, p.1-16, 2006. 
SILVA, F. A. N.; CARVALHO, R. L.; KLEIN, R. P.; QUESSADA, A. M. Posse responsável de cães no bairro Buenos Aires na cidade de Teresina (PI). ARS Veterinária, v. 25, n. 1, p.14-17, 2009.

SILVA, M. H. S.; SILVA, J. A.; MAGALHÃES, D. F.; SILVA, M. X.; MENESES, J. N. C.; MOREIRA, E. C. Caracterização demográfica e epidemiológica de cães e gatos domiciliados em Barbacena, MG. Arq. Bras. Med. Vet. Zootec., v. 62, n. 4, p. 1001-1006, 2010. SILVANO, D.; BENDAS, A. J. R.; MIRANDA, M. G. N.; PINHÃO, R.; MENDES DE ALMEIDA, F.; LABARTHE, N. V.; PAIVA, J. P. Divulgação dos princípios de guarda responsável: uma vertente possível no trabalho de pesquisa a campo. Revista Eletrônica Novo Enfoque, v. 9, n. 9, p. 64-86, 2010. Disponível em http:// www.castelobranco.br/sistema/novoenfoque/files/09/artigos/06. pdf. Acesso: 11 de novembro de 2011.
SOTO, F. R. M.; BERNARDI, F. Programa de educação continuada sobre posse responsável de cães e gatos: a integração entre a Secretaria de Educação e Saúde do município de Ibiúna - SP. Rev. Ciênc. Ext., v. 7, n. 2, p. 130-134, 2011.

VIANNA, A. T. Os suínos: criação e prática econômica. São Paulo: Nobel, 1988. 384 p.

VIEIRA, A. M. L. Programa de controle de cães e gatos do Estado de São Paulo. BEPA, ano 3, n. 25, jan. 2006. Disponível em: http:// www.cve.saude.sp.gov.br/agencia/bepa25_rg7caes.htm. Acesso em 22 de fevereiro de 2012. 